Article

\title{
Minimization of Load Variance in Power Grids-Investigation on Optimal Vehicle-to-Grid Scheduling
}

\author{
Kang Miao Tan ${ }^{1}$, Vigna K. Ramachandaramurthy ${ }^{1}$ (D) , Jia Ying Yong ${ }^{1}$ (D), \\ Sanjeevikumar Padmanaban ${ }^{2, *}$ (D), Lucian Mihet-Popa ${ }^{3}$ (D) and Frede Blaabjerg 4 \\ 1 Power Quality Research Group, Institute of Power Engineering, Department of Electrical Power Engineering, \\ Universiti Tenaga Nasional, Jalan IKRAM-UNITEN, Kajang, Selangor 43000, Malaysia; \\ tankangmiao@gmail.com (K.M.T.); vigna@uniten.edu.my (V.K.R.); yongjiaying89@gmail.com (J.Y.Y.) \\ 2 Department of Electrical and Electronics Engineering, University of Johannesburg, 2006 Auckland Park, \\ South Africa \\ 3 Faculty of Engineering, Østfold University College, Kobberslagerstredet 5, 1671 Kråkeroy-Fredrikstad, \\ Norway; lucian.mihet@hiof.no \\ 4 Centre for Reliable Power Electronics (CORPE), Department of Energy Technology, Aalborg University, \\ 9000 Aalborg, Denmark; fbl@et.aau.dk \\ * Correspondence: sanjeevi_12@yahoo.co.in; Tel.: +27-79-219-9845
}

Received: 16 September 2017; Accepted: 3 November 2017; Published: 16 November 2017

\begin{abstract}
The introduction of electric vehicles into the transportation sector helps reduce global warming and carbon emissions. The interaction between electric vehicles and the power grid has spurred the emergence of a smart grid technology, denoted as vehicle-to grid-technology. Vehicle-to-grid technology manages the energy exchange between a large fleet of electric vehicles and the power grid to accomplish shared advantages for the vehicle owners and the power utility. This paper presents an optimal scheduling of vehicle-to-grid using the genetic algorithm to minimize the power grid load variance. This is achieved by allowing electric vehicles charging (grid-to-vehicle) whenever the actual power grid loading is lower than the target loading, while conducting electric vehicle discharging (vehicle-to-grid) whenever the actual power grid loading is higher than the target loading. The vehicle-to-grid optimization algorithm is implemented and tested in MATLAB software (R2013a, MathWorks, Natick, MA, USA). The performance of the optimization algorithm depends heavily on the setting of the target load, power grid load and capability of the grid-connected electric vehicles. Hence, the performance of the proposed algorithm under various target load and electric vehicles' state of charge selections were analysed. The effectiveness of the vehicle-to-grid scheduling to implement the appropriate peak load shaving and load levelling services for the grid load variance minimization is verified under various simulation investigations. This research proposal also recommends an appropriate setting for the power utility in terms of the selection of the target load based on the electric vehicle historical data.
\end{abstract}

Keywords: electric vehicles; energy management; load variance; optimal scheduling; optimization; vehicle-to-grid

\section{Introduction}

Electric vehicles (EVs) have gained popularity due to their emission free and fuel independence characteristics. Governments across the nations have established several schemes and organizations to facilitate the electrification process of roadway vehicles in terms of the technology, market, policy and finance. The efforts from numerous parties have successfully stimulated the deployment of the 
EV market. The recent Global EV Outlook report showed improved signs of EV adoption. In the near future, the global EV stock is predicted to reach more than one hundred million by the year 2050 [1-5]. As a result, the anticipated large scale of EV charging will bring technical challenges to the power grid. Extensive studies on the harmful impacts of large scale EV charging on the power grid had been performed. The potential impacts include the overloading of power equipment, harmonics, voltage drop, voltage instability and power losses [6-16]. A review in [17] concluded that the main impact of EV integration into the power grid was the overloading issue, which further led to equipment overheating and rapid aging issues. Meanwhile, the grid power quality was assessed under various EV penetration and charging level scenarios in $[18,19]$. The results revealed that a large number of fast charging EVs would introduce serious voltage deviations and voltage instability problems.

EVs utilize relatively large capacity batteries as their energy source for the vehicle propulsion. Hence, the large scale of the grid-connected EVs can be considered as an enormous distributed energy storage in the power grid. Moreover, the potential of EVs to share energy with the power grid has created a new opportunity to improve the system reliability and sustainability. This concept, known as Vehicle-to-Grid (V2G) technology, was firstly introduced by Kempton and his research team in [20-24]. The authors proposed the adoption of V2G technology to improve the reliability of the power grid, as well as to facilitate the large scale integration of renewable energy [20]. The economic potential of EVs in providing energy support to the power grid was also studied by Kempton in [25]. The findings assured a significant revenue stream to the EV fleet for providing the V2G support. For a more accurate revenue estimation, the authors had developed a calculation model in [26] to evaluate the cost and profit in providing V2G support, mainly in the form of peak load shaving, spinning reserves and energy regulation services. Kempton and his research team also paid attention to the willingness of people to pay for EVs and their attributes in [27]. The research results suggested that EV cost needs to be reduced significantly in order to have higher EV adoption in the marketplace. Additionally, V2G management strategies and implementation steps were proposed in [28] to assist the transition of V2G technology.

The potential of the V2G concept has urged other research and development in the supporting technology for $\mathrm{V} 2 \mathrm{G}$ application. The literature has presented many potential benefits for the power grid by adopting V2G technology. These benefits include peak load shaving, load levelling, grid voltage regulation, improvement in energy efficiency and mitigation of renewable energy intermittency [29-32]. For instance, a Vehicle-to-Home (V2H) concept was presented in [33], where EVs collaborated with the renewable energy in a smart home system to minimize the pollution, fossil fuel depletion and investment cost. In addition, a study in [34] utilized EVs to support the autonomous operation mode of microgrids. During the transition to separate from the power grid, the available EVs were used by the system frequency controller as a buffering feature to stabilize the microgrid operation.

Nevertheless, the V2G implementation requires frequent charging and discharging processes which can cause extra deterioration to the EV batteries [35]. This downside has created a strong social barrier that can prevent public support for the V2G concept. Hence, optimal V2G charging and discharging scheduling with compensated incentives given to the participating EV owners will be especially crucial for the realization of this technology. Research has been carried out to develop the optimal planning and scheduling for the proper V2G execution. The complexity in managing the large amount of energy exchange between the power grid and EVs represents a challenge for a power utility. The first logical step to implement the V2G technology was proposed in [36]. The proposed unidirectional spinning reserve V2G algorithm was able to modulate the EV charging rate according to a Preference Operating Point (POP), where the minimal preliminary investment and EV batteries degradation were achieved.

On the other hand, the bidirectional V2G technology has tremendous flexibility to accomplish the EV scheduling according to the preferences of the EV owners and power grid requirements. Many researchers have proposed EV scheduling that utilizes the Grid-to-Vehicle (G2V) and Vehicle-to-Grid (V2G) operations to help the power grid in achieving various benefits [37-39]. From the 
economic standpoint, the authors in $[40,41]$ emphasized the maximization of power utility profit while developing the V2G algorithm. Meanwhile, the minimization of power system losses is also a popular topic in the V2G application. In [42], EVs were used as reactive power resources to reduce the power grid energy losses. Furthermore, V2G technology was also utilized to maximize the renewable energy generation by solving the renewable energy intermittency issue $[43,44]$. Intelligent optimization algorithms were proposed by the authors in [45-47] to solve the renewable energy intermittency problem while maximizing the power grid energy efficiency.

Various optimal V2G scheduling strategies have been introduced in the literature to minimize the power grid load variance $[48,49]$. This concept is well known for its effectiveness in reducing power grid operation losses [50]. In general, this is achieved by enabling the grid-connected EVs to absorb the extra electricity during the power grid valley load period and feed the energy back to the power grid during the peak load period [51-54]. For instance, a V2G scheduling algorithm was proposed in [55] to perform power grid load shaving and valley filling operations using grid-connected EVs. The operation was achieved by regulating the power grid load at the target load pre-determined in the scheduling algorithm. A similar demand side management concept was adopted in [56], where considerable savings and emissions reduction were demonstrated by the results. Meanwhile, the authors in [57] proposed a peak shaving algorithm to reduce the peak demand of the power grid. The application of this algorithm has shown good potential in extending the lifespan of transformers, as well as maintaining a healthy grid operation voltage profile. Another peak shaving strategy was introduced in $[58,59]$, which provided dynamic adjustments in EVs discharging rate without affecting the battery usage for EV traveling purpose. This strategy limited the maximum load demand by utilizing the extra energy in the grid-connected EVs for power grid support. In these literatures, many of the proposed V2G scheduling for power grid load variance minimization utilized a preset target loading in the scheduling algorithm. Nevertheless, most of the related studies have not discussed the methodology used in determining these targets. Inaccurate setting of this target loading will reduce the effectiveness of the $\mathrm{V} 2 \mathrm{G}$ algorithm to achieve the minimization of load variance. The selection of this target loading can be a challenging task, as the power grid and grid-connected EVs are dynamic in nature. Thus, this paper will focus on the development of a V2G optimization algorithm, as well as analyzing the influence of different target load curves on the performance of the proposed algorithm.

This paper presents a G2V/V2G optimization algorithm, which is focused on the minimization of grid load variance by performing load levelling and peak load shaving using the available grid-connected EVs. During the event where the actual power grid loading is lower than the target loading, EVs are allowed to receive charging power from the power grid. This G2V operation falls under the load leveling scenario. Meanwhile, when the actual power grid loading is larger than the target loading, EVs are encouraged to discharge for power grid support. This V2G operation is called the peak load shaving scenario. In general, this paper will present the proposed algorithm, which consists of G2V and V2G operations as the V2G optimization algorithm. The V2G algorithm instructs EV charging and discharging operations according to the proposed objective function with the aim of minimizing the difference between the actual power grid loading and target loading. The V2G optimization algorithm includes thorough consideration of both power grid and EV constraints. The algorithm can also deliberate the V2G scheduling by considering the uncertain mobility characteristics of EVs, which have random initial State of Charge (SOC) and grid connection duration, as well as the dynamic grid connection probability. In addition, extensive analyses are conducted to investigate the effect of different target load curves and various average initial SOC of EV batteries on the performance of the proposed V2G optimization algorithm. A performance index was introduced to compare and evaluate the success rate of each optimized scenario. Then, a proper selection of the V2G target load curve based on the average initial SOC of the available grid-connected EV batteries is recommended. In summary, the contributions of this paper include: (i) the development of a V2G optimization algorithm to minimize grid load variance via peak load shaving and load 
levelling, and (ii) a performance analysis of the proposed V2G optimization under various target load and average initial SOC of EV batteries.

The rest of the paper is organized into sections. Section 2 describes the power grid model for the implementation of V2G optimization algorithm. In Section 3, the detailed formulation of the objective function, constraints and optimization algorithm are presented. The simulation results to validate the effectiveness of the proposed V2G optimization algorithm are discussed in Section 4. Section 5 concludes the paper.

\section{Power Grid Model for V2G Implementation}

The implementation of V2G technology requires extensive planning and careful management in order to ensure the reliability of the power grid. In the initial stage of the V2G implementation, the V2G location shall be well planned for the proper V2G application. For instance, the quantity of EV mobility within the V2G location is crucial for the practicality of V2G technology. In this paper, an adequate quantity of the grid-connected EVs was required to ensure the proper amount of EV batteries' storage capacities was available to absorb or deliver the power during the interaction with the power grid. This is to ensure an average distributed amount of EVs shall be accessible within the V2G location throughout the day. Thus, the selected V2G location shall be a relatively large township, which consisted of both residential and commercial areas to ensure a sufficient and consistent EV mobility throughout the day. Figure 1 presents an intelligent township for the V2G implementation consisting of the commercial offices, residential areas and smart V2G car parks. The components to realize the V2G technology are also shown in Figure 1. For instance, the township was equipped with the dual communication system across all the commercial loads, residential loads and smart V2G car parks with the local aggregator. Furthermore, the bidirectional V2G chargers were installed in the smart V2G car parks, which allowed each EV to charge from and discharge to the power grid.

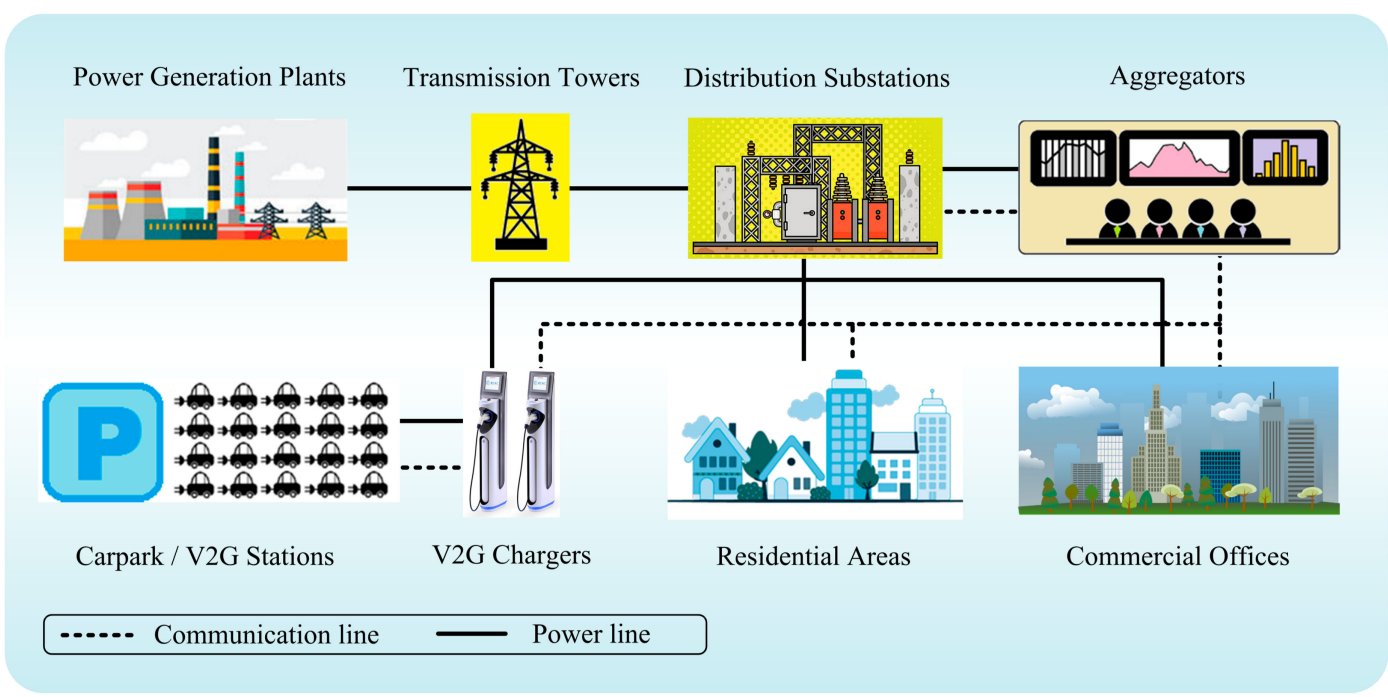

Figure 1. Intelligent Vehicle-to-Grid (V2G) township.

Figure 2 shows the single-line diagram of a generic township used in this paper for the implementation of V2G technology. The generic township was a typical radial configured power distribution grid. This township had a total of 200 units of the commercial offices and 800 units of the residential condominiums. The maximum demand for each commercial office was $15 \mathrm{~kW}$, whilst $10 \mathrm{~kW}$ for each residential condominium. All the loads within the generic township were supplied via the 22 substations, where each substation had a step down transformer rated at $1 \mathrm{MW}$. Several assumptions were made for the V2G optimization algorithm and are listed as follows: 
- All the residential, commercial and EV loads were evenly distributed to each substation in the proposed generic township.

- The town had a total of 1800 EV mobility daily, which includes EVs from the generic and nearby townships.

- The smart car parks had sufficient parking spaces equipped with the bidirectional V2G chargers.

- The aggregator had the appropriate bidirectional communication system to monitor the load profile of each substation and access the information of each EV, such as the EV availability and SOC level of EV battery.

- The aggregator was given the full authority to manage and control the amount of power sharing between the EVs and power grid.

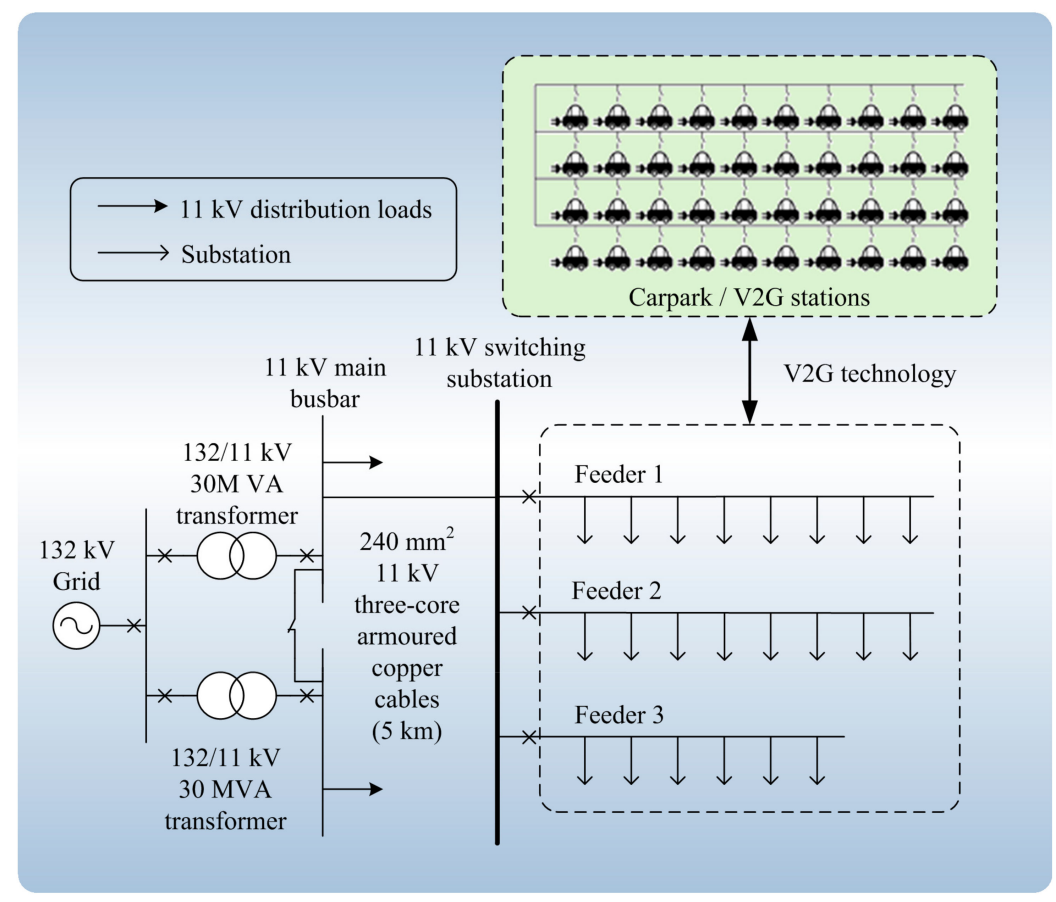

Figure 2. Single-line diagram of a generic township.

\section{Problem Formulation}

The implementation of V2G technology in the power grid usually involves multiple conflicting objectives, which are plagued with numerous uncertainties and nonlinearities. Therefore, the utilization of the optimization technique is crucial to execute the V2G concept in the power grid. In this paper, the Genetic Algorithm (GA) optimization technique is employed to solve the V2G optimization problem. This section discusses the objective function and constraints for the optimization problem.

\subsection{Objective Function}

In this paper, the proposed V2G optimization algorithm has the objective to optimize the grid-connected EV charging and discharging power in order to minimize the power grid load variance. A generalized daily power load curve is depicted in Figure 3. Besides, the desired grid loading is achieved by performing peak load shaving and load levelling to minimize the variance between the power grid loading and target loading as illustrated in Figure 3. The proposed V2G optimization algorithm is performed by enabling the $\mathrm{EV}$ charging during the period where the power grid loading is less than the target loading (G2V operation). On the contrary, EVs are required to discharge the energy from the batteries when the power grid loading is larger than the target loading (V2G operation). No power flows between the EVs and power grid when the target loading is equal to the power 
grid loading. Equations (1) and (2) express the objective function in terms of grid load variance, target loading, charging and discharging rate:

$$
\begin{gathered}
\min \Delta P=P_{\text {target }}(t)-P_{\text {load }}(t)-P_{\mathrm{EV}}(t) \\
P_{\mathrm{EV}}(t)=\left\{\begin{array}{cl}
\left(\sum_{n=1}^{N} A_{n} K_{n}\right) \times P_{\mathrm{EV}, \text { charging }} & , \text { when } P_{\text {load }}<P_{\text {target }} \\
\left(\sum_{n=1}^{N} A_{n} K_{n}\right) \times P_{\mathrm{EV}, \text { discharging }} & , \text { when } P_{\text {load }}>P_{\text {target }} \\
0 & \text {, when } P_{\text {load }}=P_{\text {target }}
\end{array}\right.
\end{gathered}
$$

where $\Delta P$ is the grid load variance, $t$ is time, $P_{\text {target }}$ is the target loading, $P_{\text {load }}$ is the existing load of the power grid, $P_{\mathrm{EV}}$ is the total power of EV loads/sources, $n$ is the EV index, $N$ is the maximum EV index, $A_{n}$ is the availability of $n$th EV for the V2G application, $K_{n}$ is the indicator of $n$th EV for $\mathrm{V} 2 \mathrm{G}$ application, $P_{\mathrm{EV} \text {,charging }}$ is the $\mathrm{EV}$ charging rate, and $P_{\mathrm{EV} \text {,discharging }}$ is the $\mathrm{EV}$ discharging rate. In Equation (1), the grid load variance $(\Delta P)$ was minimized by optimizing the number of grid-connected EV to charge or discharge during valley load and peak load period, respectively. The determined optimal grid-connected EV numbers are then reflected in the indicator of $n$th EV for V2G application $\left(K_{n}\right)$. Meanwhile, $A_{n}$ refers to the availability of $n$th EV to the power grid prepared for the V2G application. This variable depends on the dynamic EV mobility characteristics, where the detailed EV grid-connection probability is discussed in Section 3.2.3. In the condition where $K_{n}$ and $A_{n}$ are available, the $n$th EV will be instructed to charge or discharge the battery.

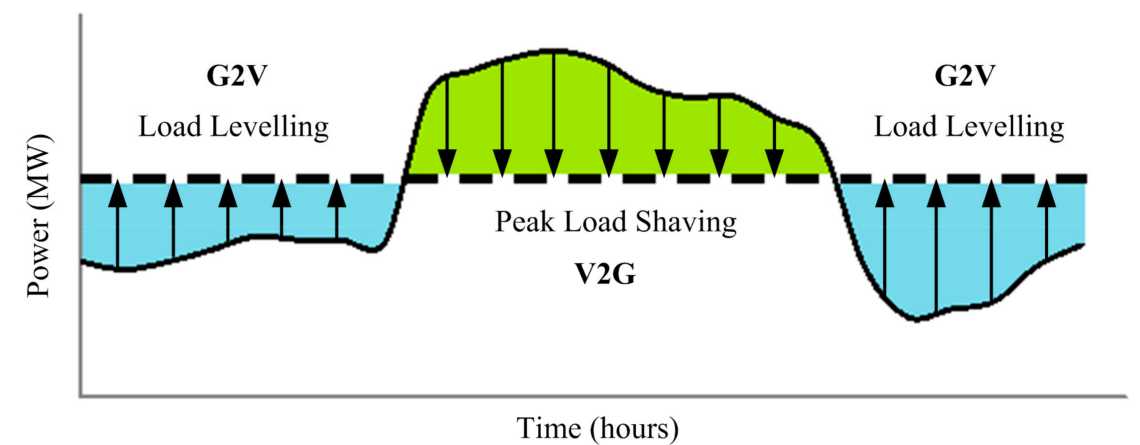

Figure 3. The concept of peak load shaving and load levelling.

\subsection{Optimization Constraints}

The operation of V2G system is restricted under plenty of system constraints and uncertainties. Therefore, the proposed V2G optimization algorithm required the compliance with these power grid and EV constraints.

\subsubsection{Power Balance}

The important power grid constraint to be considered in the proposed V2G optimization algorithm is the power balance between the grid generation and demand. The supplied power from the generation plants and distributed EV battery sources must satisfy the power grid load and EV charging demands:

$$
P_{\text {grid }}(t)+\sum_{n=1}^{N} A_{n} K_{n} P_{\text {EV }, \text { discharging }}(t)=P_{\text {load }}(t)+\sum_{n=1}^{N} A_{n} K_{n} P_{\mathrm{EV}, \text { charging }}(t)
$$

where $P_{\text {grid }}$ is the active power from the generation plant. 


\subsubsection{SOC of EV Battery}

The SOC level of EV battery is one of the EV constraints which must be kept within certain limits during the V2G operation. It is important to establish these limits for two reasons. The first reason is to protect the health of the battery. Studies show that the SOC level of a lithium ion battery should best to be limited to a $60 \%$ swing (between $30 \%$ and $90 \%$ or $25-85 \%$ ) to minimize the battery health degradation $[60,61]$. The second reason to keep the SOC level of the EV battery within certain limits is to reserve a certain amount of energy for the EV travel usage. Therefore, by taking both reasons into consideration, each EV is prevented from discharging if the battery $\mathrm{SOC}$ is lower than the $S O C_{\min }$ which is set at $55 \%$. Meanwhile, the EV charging process is only allowed if the SOC level of each EV battery is below the $S O C_{\max }$, which is set at $90 \%$ to prevent the battery overcharging issue. Both of the EV charging and discharging processes are allowed if the battery $S O C$ is within the $S O C_{\min }$ and $S O C_{\max }$ :

$$
\begin{gathered}
S O C_{n} \leq S O C_{\min } \text {, allow for charging only } \\
S O C_{\min } \leq S O C_{n} \leq S O C_{\text {max }} \text {, allow for charging and discharging } \\
S O C_{n} \geq S O C_{\max } \text {, allow for discharging only }
\end{gathered}
$$

where $S C_{n}$ is the battery SOC for $n$th EV.

\subsubsection{EV Grid Connection Probability}

The feasibility of V2G technology requires EVs to be connected to the power grid. Nevertheless, each EV can be connected to the power grid at different arrival and departure times in the car park, which will lead to the dynamic EV mobility characteristics [62-69]. Hence in this paper, the EV grid connection probability is estimated based on the driving behaviour of the township's residents and commercial workers. In Figure 4, the EV grid connection probability of the residential car park showed that more EVs are available in the car park, since the beginning of the day until 06:00 o'clock in the morning.

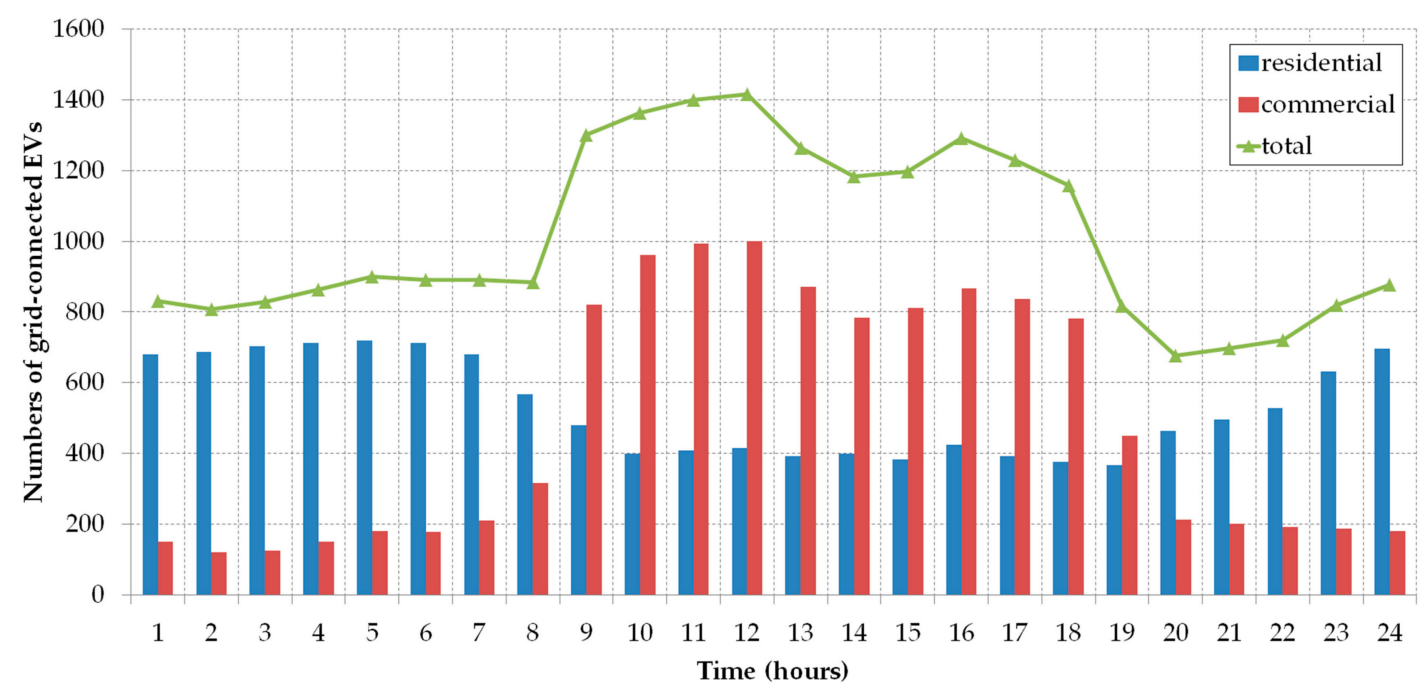

Figure 4. Electric Vehicle (EV) grid connection probability of the township.

Later on, most of the EV owners are away to their workplaces and schools. From 18:00 o'clock onwards, the residents started to return home and occupied the residential car park. On the other hand, the EV grid connection probability of the commercial car parks depicted that most of the parking spaces are occupied during the daytime office hours. Other than these periods, the commercial car park is almost empty. The combination of the EV grid connection probability of the residential and 
commercial car parks gave the total EV availability in the proposed generic township, as shown in Figure 4.

$$
\begin{gathered}
A_{n}=1 \text {, when } n \text {th EV was connected to the power grid } \\
A_{n}=0 \text {, when } n \text {th EV was not connected to the power grid }
\end{gathered}
$$

\subsubsection{EV Power Exchange Rate}

The power exchange rate between the EV batteries and power grid shall be restricted within a safe margin to protect the safety and health of EV batteries throughout the power exchange periods. A common EV battery available in the market is considered in this research. The EV battery used in this paper a lithium-ion battery, which has the rated capacity of $50 \mathrm{Ah}$. The power exchange rate of each EV battery is limited below $3.3 \mathrm{~kW}$, which is the typical power rating for slow charging:

$$
\begin{gathered}
P_{\mathrm{EV}, \text { charging }} \leq P_{\mathrm{EV}, \text { max }} \\
P_{\mathrm{EV} \text {,discharging }} \leq-P_{\mathrm{EV} \text {,max }}
\end{gathered}
$$

where $P_{\mathrm{EV}, \max }$ is the maximum EV exchange rate.

\subsection{Optimization Algorithm}

The proposed V2G optimization algorithm is implemented in MATLAB software tool (R2013a, MathWorks, Natick, MA, USA) as shown in Figure 5.

In order to handle a large number of parameters, the GA optimization technique is adopted. The GA is an iteration method that is capable of searching for the global optimal solution within an execution time limit. Furthermore, the GA is inspired by the living organism evolutionary process, which requires the representation of a potential solution as the genetic chromosome. A proper fitness function is utilized to compute and evaluate the score of this genetic chromosome. After the evaluation, the GA principle is repeated again to reproduce a new generation of chromosome until this iteration converges to an optimal solution.

In the initial stage of the proposed V2G algorithm, the system parameters are obtained and updated into the database. With this information, the GA algorithm evaluates the fitness function of the grid load variance minimization, which later produce the next generation of solution. The evaluation repeated itself until the iteration converged to an optimal EV charging or discharging power. This optimization process is bound by the power grid and EV constraints. Meanwhile, the V2G optimization algorithm is executed for every hour.

With respect to the constraint limits, the proposed V2G optimization algorithm performed the peak load shaving and load levelling services by utilizing the EV battery storages in order to minimize the load variance, as it is shown in Figure 5. 


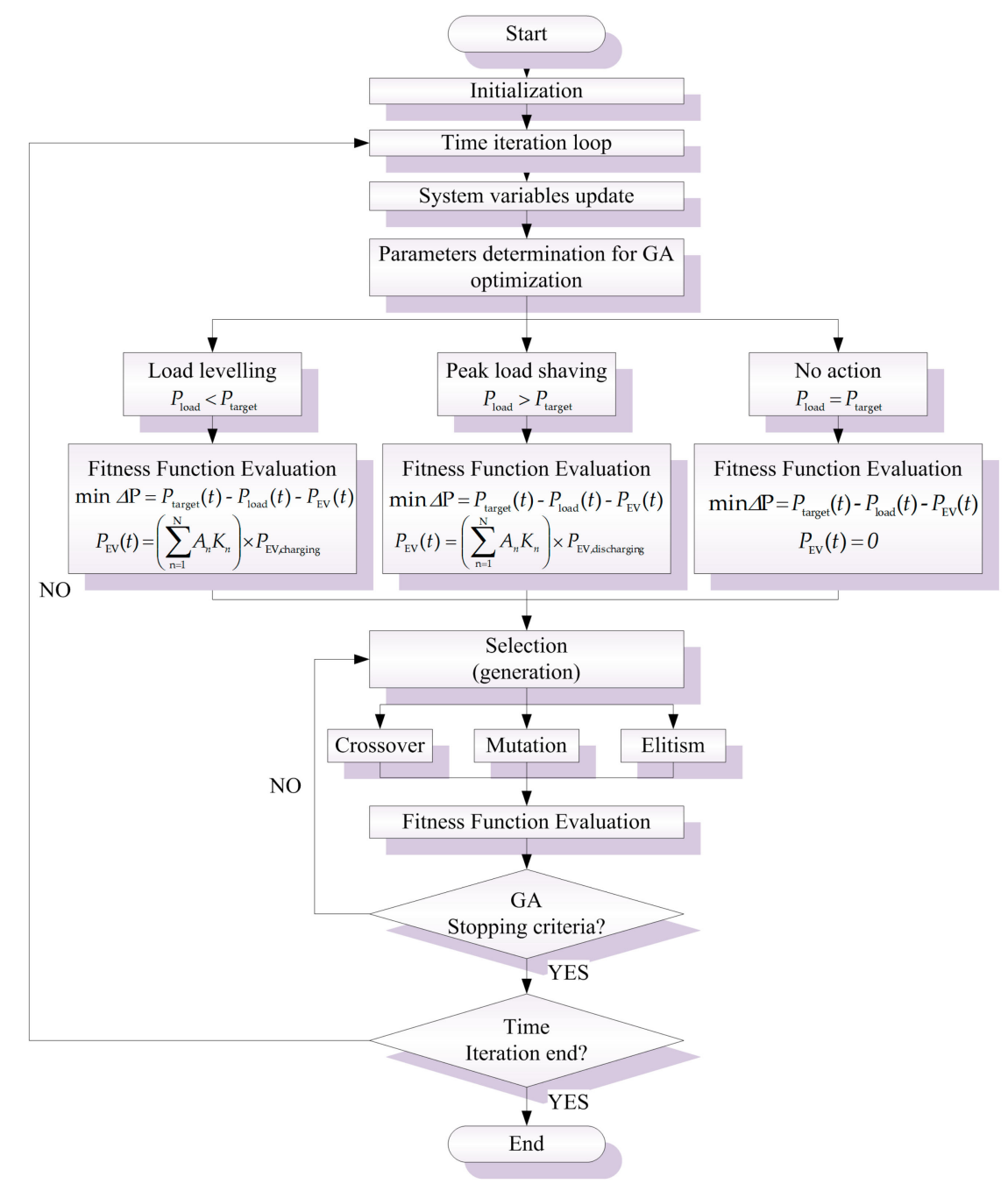

Figure 5. Flowchart for the proposed V2G optimization algorithm.

\section{Results and Discussion}

In this section, the feasibility of the proposed V2G optimization algorithm that was investigated under different scenarios was elaborated. Various average initial SOC of EV batteries $\left(S O C_{i, a v e}\right)$ and target load curve in percentage $\left(T L C_{p c t}\right)$ were considered to examine the performance of the proposed V2G optimization algorithm. The definitions of the $S O C_{i, a v e}$ and $T L C_{p c t}$ are shown in Equations (11) and (12), correspondingly:

$$
\text { Average initial SOC of EV Batteries }\left(S O C_{i, a v e}\right)=\frac{\sum_{n=1}^{N} K_{n} A_{n} S O C_{n}}{N}
$$

$$
\text { Percentage of Target Load Curve }\left(T L C_{p c t}\right)=\frac{\text { target load curve }}{\text { peak load }} \times 100 \%
$$

All the scenarios were conducted in the generic commercial-residential township as depicted in Figure 2. Figures 6-8 present the comparison between the optimized power load curves and original power load curves, where the $T L C_{p c t}$ were set at $50 \%, 55 \%$ and $60 \%$, respectively. In each scenario, different $S O C_{i, a v e}$ of $40 \%, 50 \%, 60 \%, 70 \%$ and $80 \%$ were applied. Based on the preset values of the $S O C_{i, a v e}$ and $T L C_{p c t}$, different optimized power load curves were acquired with the implementation of the proposed V2G optimization algorithm. For instance, the scenario in Figure 6a shows that the 
$S O C_{i, a v e}$ was set at $40 \%$ and the $T L C_{p c t}$ was kept at $50 \%$ of the peak loading of the power load curve. Since the $S O C_{i, a v e}$ was low, the proposed V2G optimization algorithm can perform the load levelling service by the EV charging operation, but not the EV discharging operation for the peak load shaving service. In contrast, reversed outcomes can be observed for scenario in Figure 8e due to higher $\mathrm{SOC}_{i, a v e}$ and $T L C_{p c t}$.

(a)

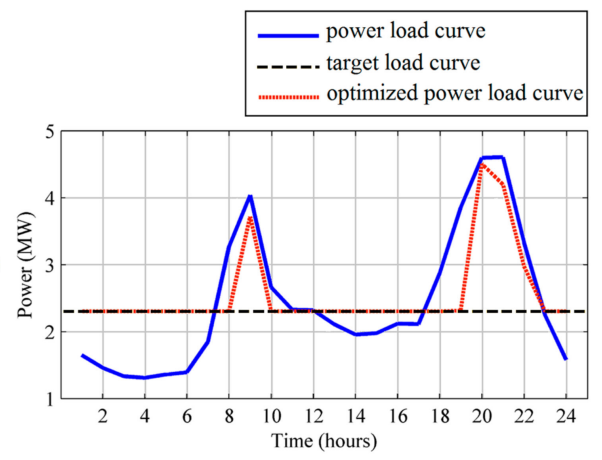

(b)
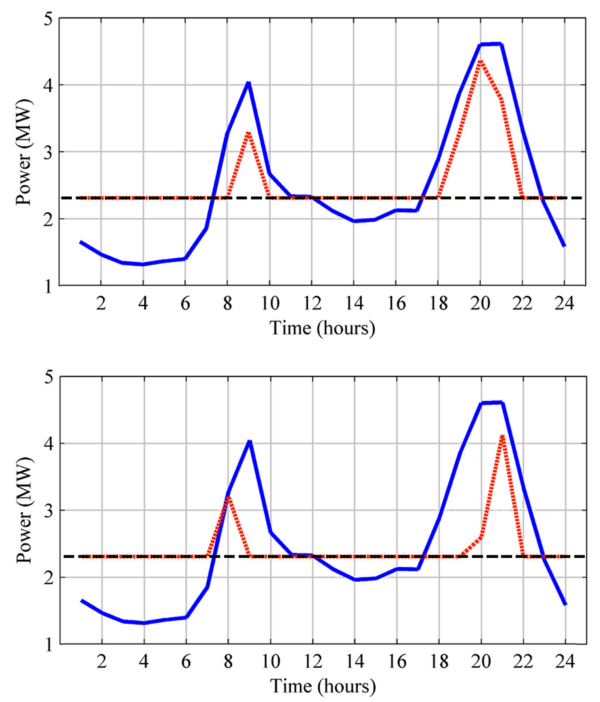

(d)

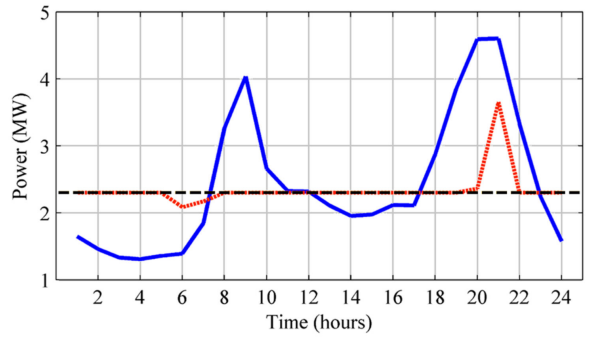

(e)

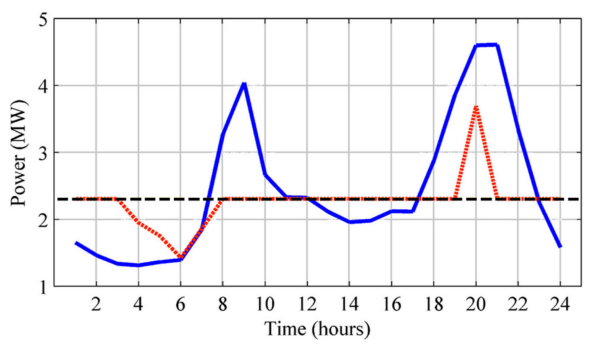

Figure 6. Optimized power load curves with $50 \% T L C_{p c t}$ and $S O C_{i, a v e}$ of (a) $40 \%$, (b) $50 \%$, (c) $60 \%$, (d) $70 \%$ and (e) $80 \%$. 
(a)

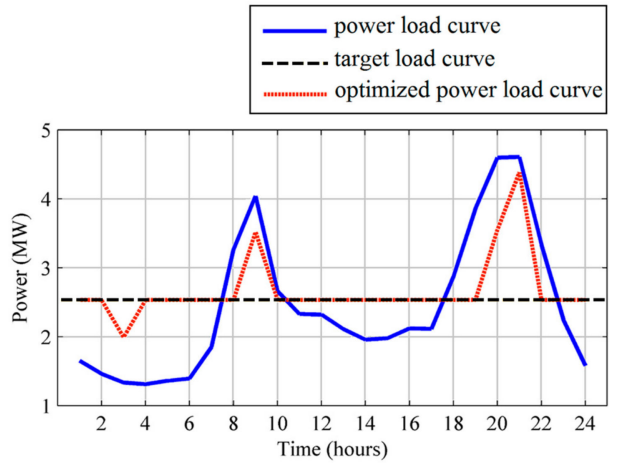

(b)

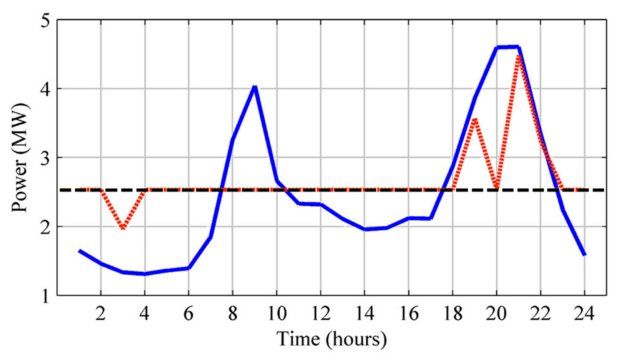

(c)

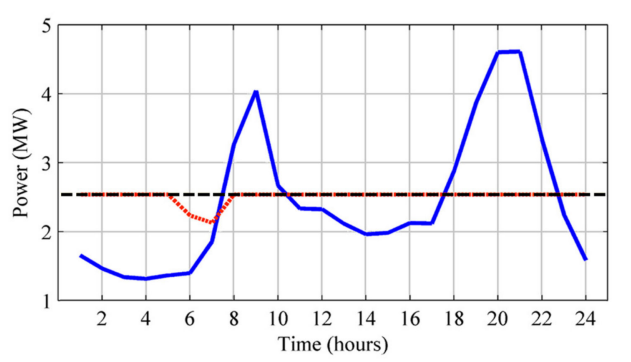

(d)

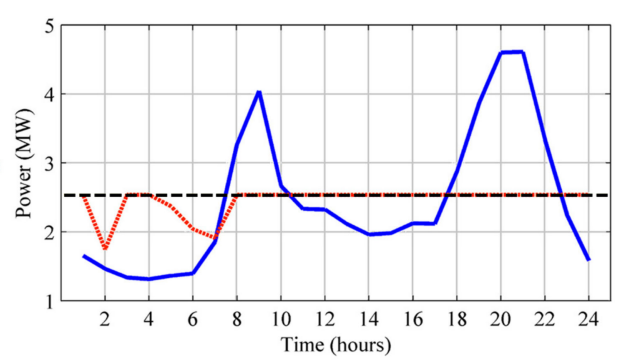

(e)

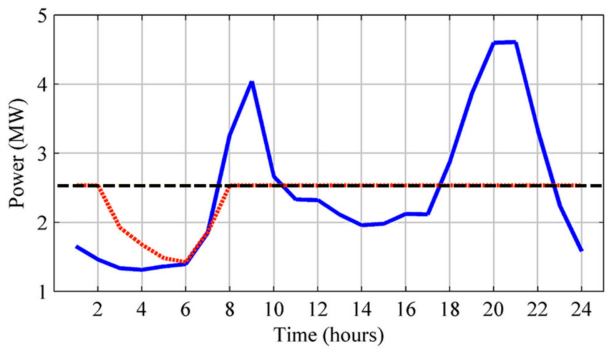

Figure 7. Optimized power load curves with $55 \% T L C_{p c t}$ and $S O C_{i, a v e}$ of (a) $40 \%$, (b) $50 \%$, (c) $60 \%$, (d) $70 \%$ and (e) $80 \%$. 
(a)

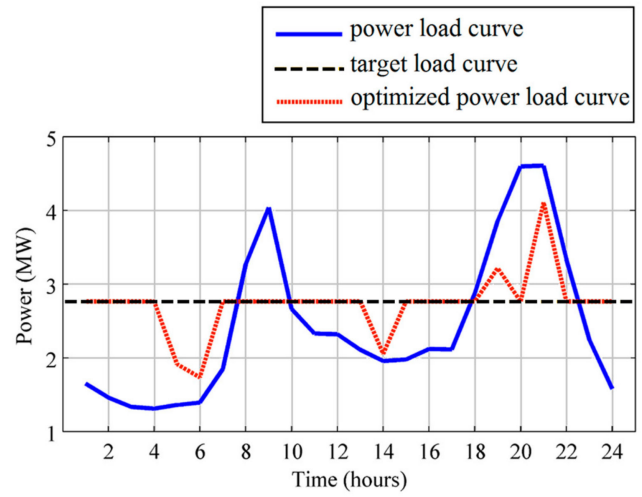

(b)

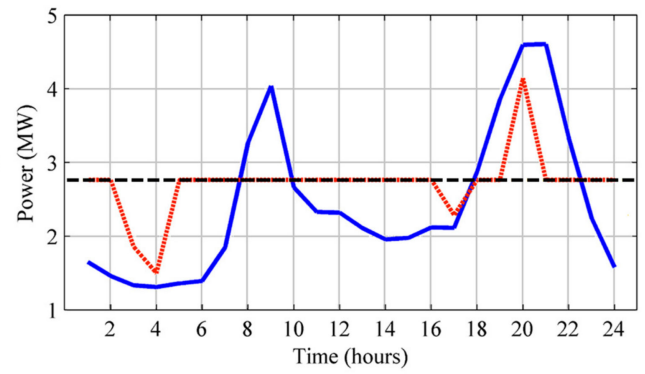

(c)

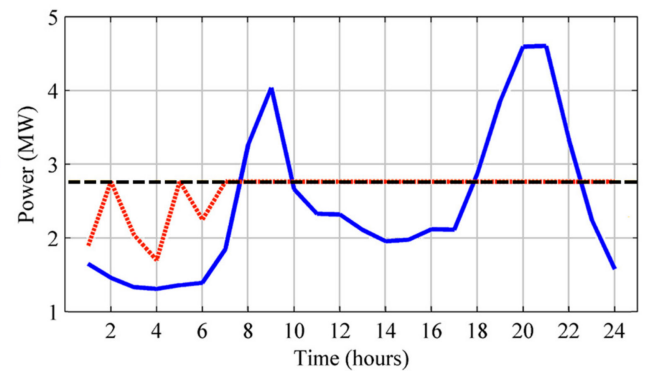

(d)

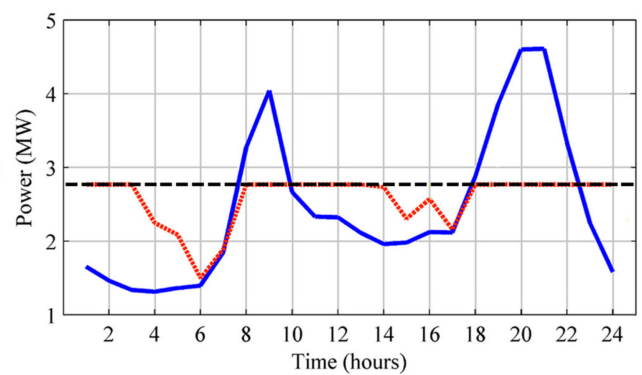

(e)

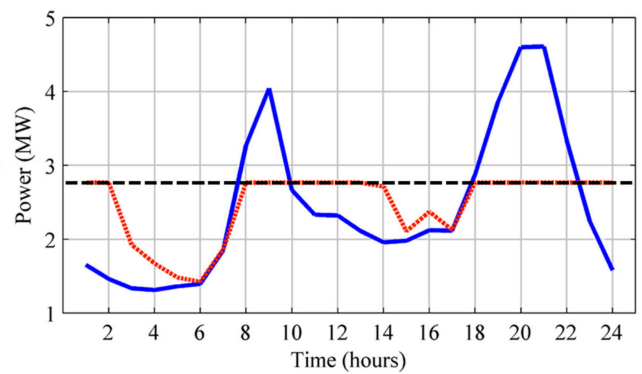

Figure 8. Optimized power load curves with $60 \%$ TLC $p$ at and $S O C_{i, a v e}$ of (a) $40 \%$, (b) $50 \%$, (c) $60 \%$, (d) $70 \%$ and (e) $80 \%$.

The consideration of various values of $S O C_{i, a v e}$ and $T L C_{p c t}$ had led to different optimization results. In certain scenarios, the optimized load curves were not completely flat due to the fact the 
required energy demand for peak load shaving and load levelling services exceeded the available energy capacity of the EV batteries. In other words, EV batteries cannot supply or absorb the required energy for the minimization of grid load variance. Therefore, an index denoted as Performance Index was introduced to allow better comparison among the optimized power load curves. The Performance Index indicated the percentage of successful operations of the peak load shaving, load levelling or combination of both to achieve the preset target load curve over a day. The Performance Index can range from zero to one, where greater value indicates higher successful rate. Table 1 presents the Performance Index of the proposed V2G optimization algorithm for all the scenarios depicted in Figures 6-8. Three sets of the Performance Index were calculated for peak load shaving, load levelling and both services together.

With reference to the Performance Index in Table 1, the capability of peak load shaving was enhanced while the capability of load levelling was reduced with the increase of $S O C_{i, a v e}$. These situations were due to the increase in the available EV energy to be discharged for the peak load shaving, as well as the reduced need of EV batteries to receive charging from the power grid and thus limited the load levelling. Likewise, the occurrence of similar trends can be determined with the increase of the $T L C_{p c t}$, where more peak load shaving service can be accomplished while fewer load levelling can be achieved using the proposed optimization algorithm. The reason was due to the required EV discharging energy for the peak load shaving was greatly reduced when the set point of $T L C_{p c t}$ was increased. However, the load levelling became more difficult to be achieved due to the significant increase of energy required to be charged into the EV batteries.

Table 1. Performance Index of the V2G optimization algorithm under various scenarios.

\begin{tabular}{|c|c|c|c|c|c|c|}
\hline \multirow{2}{*}{ Region } & \multirow{2}{*}{ Percentage of Target Load Curves $\left(T L C_{p c t}\right)$} & \multicolumn{5}{|c|}{ Average Initial SOC of EV Batteries $\left(S O C_{i, a v e}\right)$} \\
\hline & & $40 \%$ & $50 \%$ & $60 \%$ & $70 \%$ & $80 \%$ \\
\hline \multirow{3}{*}{ Peak load shaving } & $50 \%$ & 0.429 & 0.496 & 0.724 & 0.870 & 0.872 \\
\hline & $55 \%$ & 0.571 & 0.590 & 1.000 & 1.000 & 1.000 \\
\hline & $60 \%$ & 0.751 & 0.809 & 1.000 & 1.000 & 1.000 \\
\hline \multirow{3}{*}{ Load levelling } & $50 \%$ & 1.000 & 1.000 & 1.000 & 0.956 & 0.713 \\
\hline & $55 \%$ & 0.953 & 0.950 & 0.937 & 0.818 & 0.623 \\
\hline & $60 \%$ & 0.830 & 0.826 & 0.791 & 0.694 & 0.526 \\
\hline \multirow{3}{*}{ Overall } & $50 \%$ & 0.667 & 0.706 & 0.839 & 0.905 & 0.806 \\
\hline & $55 \%$ & 0.785 & 0.792 & 0.965 & 0.898 & 0.789 \\
\hline & $60 \%$ & 0.805 & 0.821 & 0.858 & 0.793 & 0.679 \\
\hline
\end{tabular}

Other than the two individual set of Performance Index values for peak load shaving and load levelling, the overall Performance Index shows the success percentage for both peak load shaving and load levelling. The shaded region of the overall Performance Index in Table 1 indicates the best $T L C_{p c t}$ to be selected with respect to the $S O C_{i, a v e}$. Figures 9 and 10 illustrate the Performance Index under various scenarios and gives a clearer perception on the overall optimized scenarios. The peak point in Figure 10 shows the best optimized scenario with the overall Performance Index of 0.965, which dropped under the $60 \%$ of $S O C_{i, a v e}$ and $55 \%$ of $T L C_{p c t}$ category. This has verified that the selection of target loading for the V2G optimization algorithm played a significant role in ensuring the performance of the algorithm.

A detailed analysis on the best scenario is further presented in Figure 11. With the implementation of the proposed V2G optimization algorithm, the achieved optimized power load curve for the category of $60 \%$ of $S O C_{i, a v e}$ and $55 \%$ of $T L C_{p c t}$ is shown in Figure 11a. The optimized power load curve has almost met all the target loadings throughout the day, except during the periods from 05:00 to 08:00 o'clock.

Figure $11 \mathrm{~b}$ presents a clearer insight to explain the operations during these periods. The bar graphs in the positive and negative regions in Figure $11 \mathrm{~b}$ depict the maximum available capacity of the EV batteries and stored energy for the load levelling and peak load shaving, correspondingly. These bar graphs were obtained by considering all the constraint limits as specified in Section 3.2 and therefore, served as the limits for the optimization process. The curve shown in Figure $11 \mathrm{~b}$ presents the 
optimized EV charging and discharging power required to achieve the optimized power load curve as shown in Figure 11a. During the periods from 05:00 to 08:00 o'clock, the optimized EV charging power had reached the maximum limit of the available capacity of EV batteries for the load levelling service. Consequently, the load levelling service was not completely achieved in the optimization process.

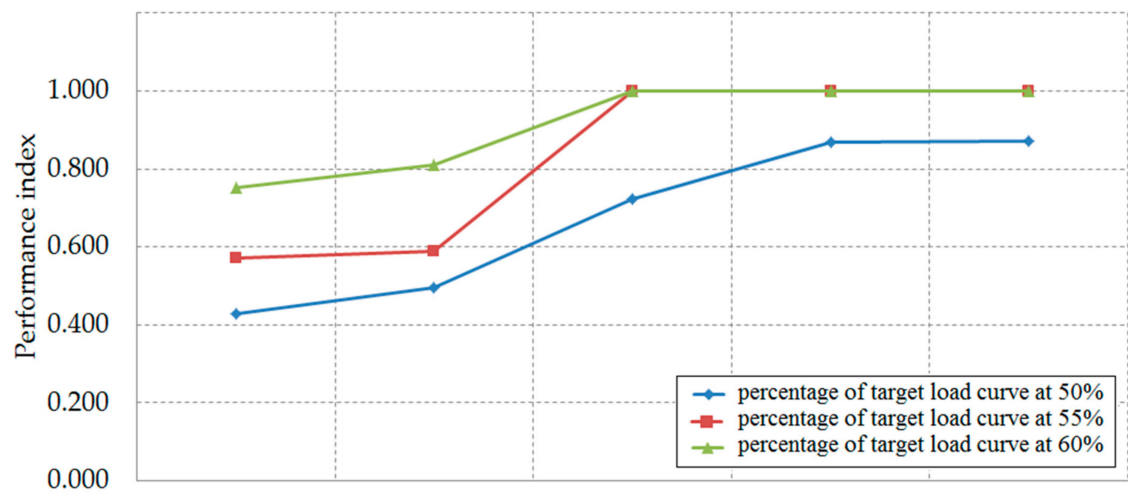

40

50

60

70

80

Average initial SOC of EV batteries (\%)

(a)

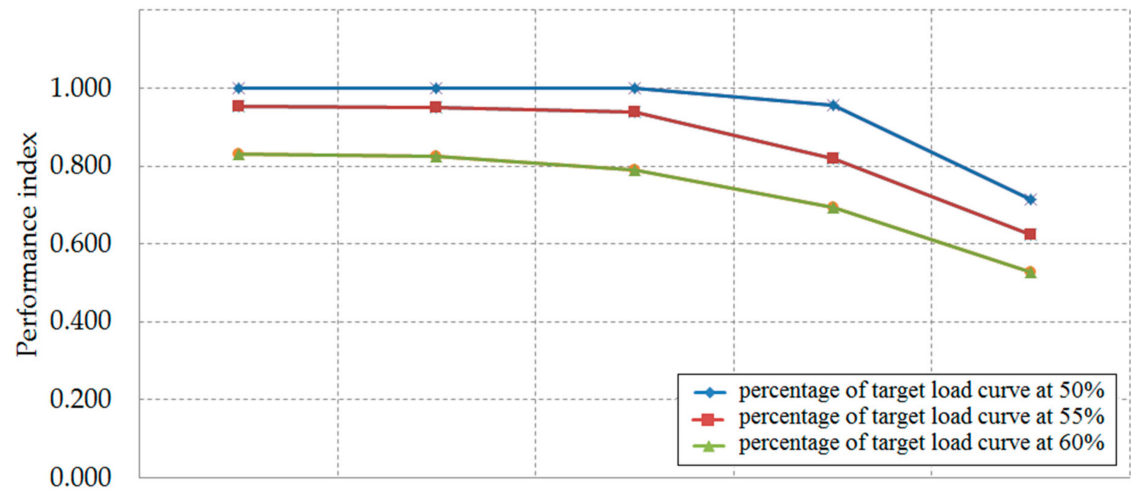

40

50

60

70

80

Average initial SOC of EV batteries (\%)

(b)

Figure 9. Performance Index under various scenarios: (a) peak load shaving and (b) load levelling.

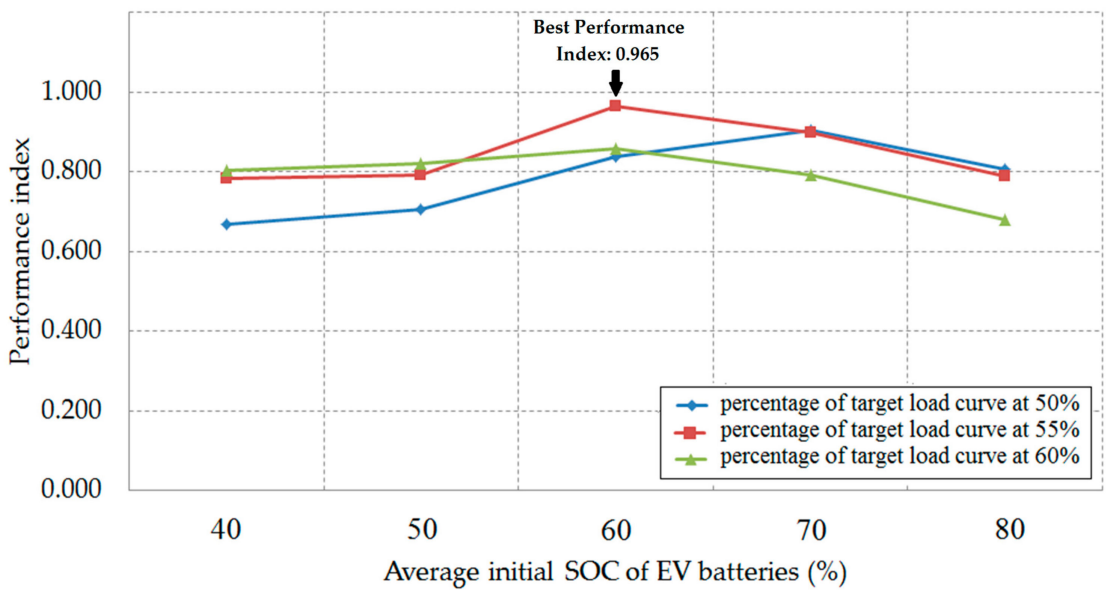

Figure 10. Overall Performance Index under various scenarios. 


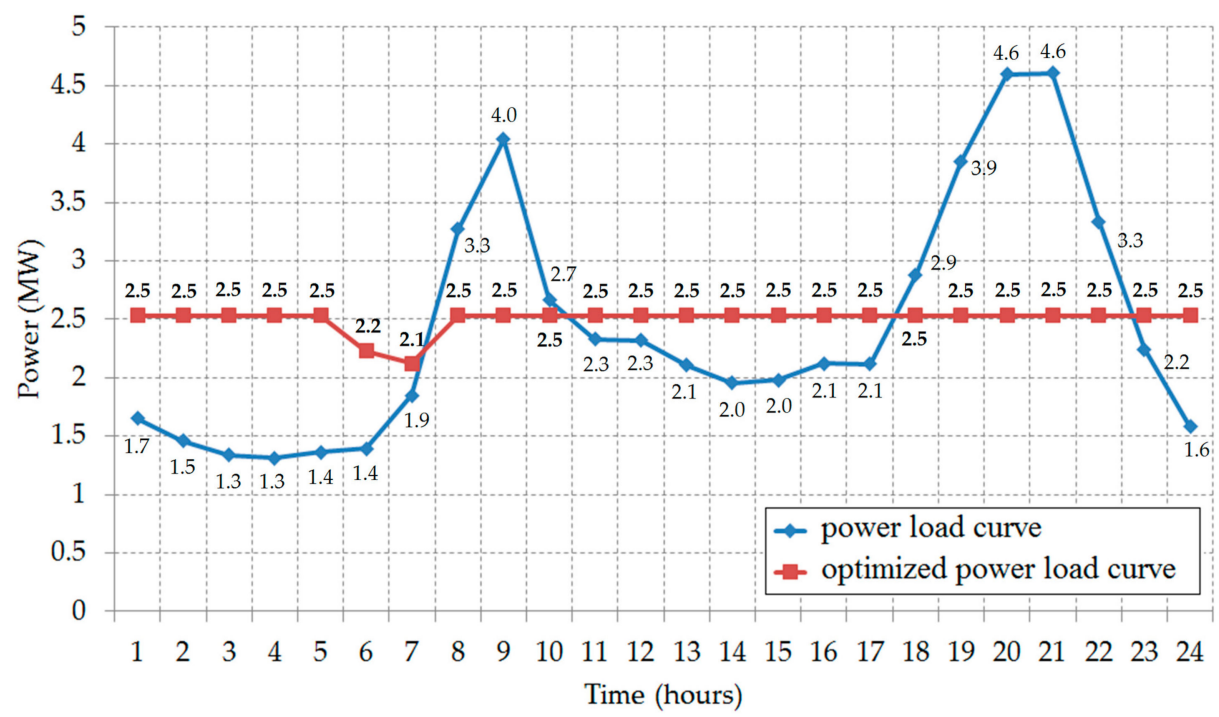

(a)

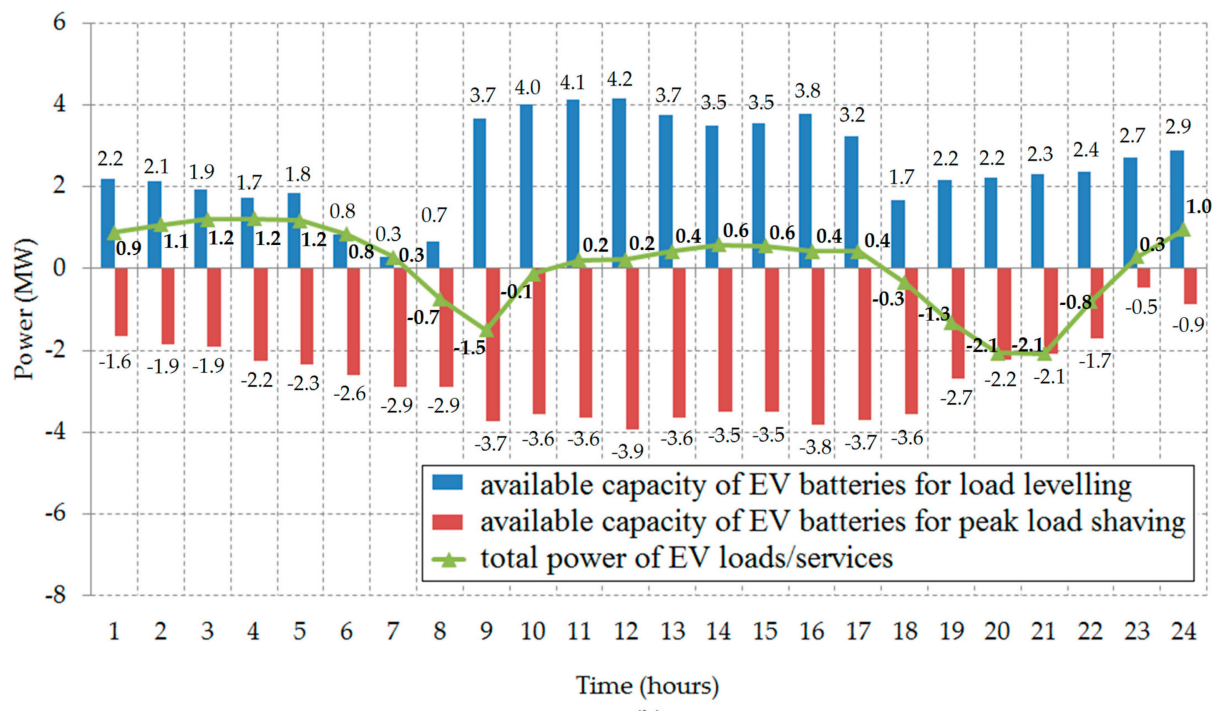

(b)

Figure 11. Detailed description of the best optimized scenario: (a) optimized power load curve (b) optimized EV charging and discharging power within constraint limits.

Figure 12 shows the SOC status of some random selected EVs under the best optimized scenario. During the load levelling periods, all the EVs experienced the charging process, except for the EVs with the SOC level higher than the $S O C_{\max }$ of $90 \%$. Meanwhile, all the EVs discharged their battery energy during the peak shaving periods, due to having all the SOC levels of EV batteries higher than the $S O C_{\min }$ of $55 \%$. Another observation from Figure 12 is that the EVs participating in the V2G optimization program had the tendency to reach to a similar SOC level at the end of the optimization process. These findings indicated that the proposed V2G optimization algorithm can flatten the power load curve with respect to the pre-determined SOC constraints.

The performance of the proposed V2G optimization algorithm was compared with other algorithms in the latest literature. A comparative parameter defined as the percentage improvement of 
peak and valley load difference, $P_{i}$ was introduced to assess the algorithm performances that were conducted under different scopes and conditions. The formulation of $P_{i}$ is expressed in (13):

$$
P_{i}=\left|\frac{P_{d, a f t e r}-P_{d, \text { before }}}{P_{d, \text { before }}}\right| \times 100 \%
$$

where $P_{d, \text { after }}$ is the peak and valley load difference after V2G optimization and $P_{d, b e f o r e}$ is the peak and valley load difference before V2G optimization.

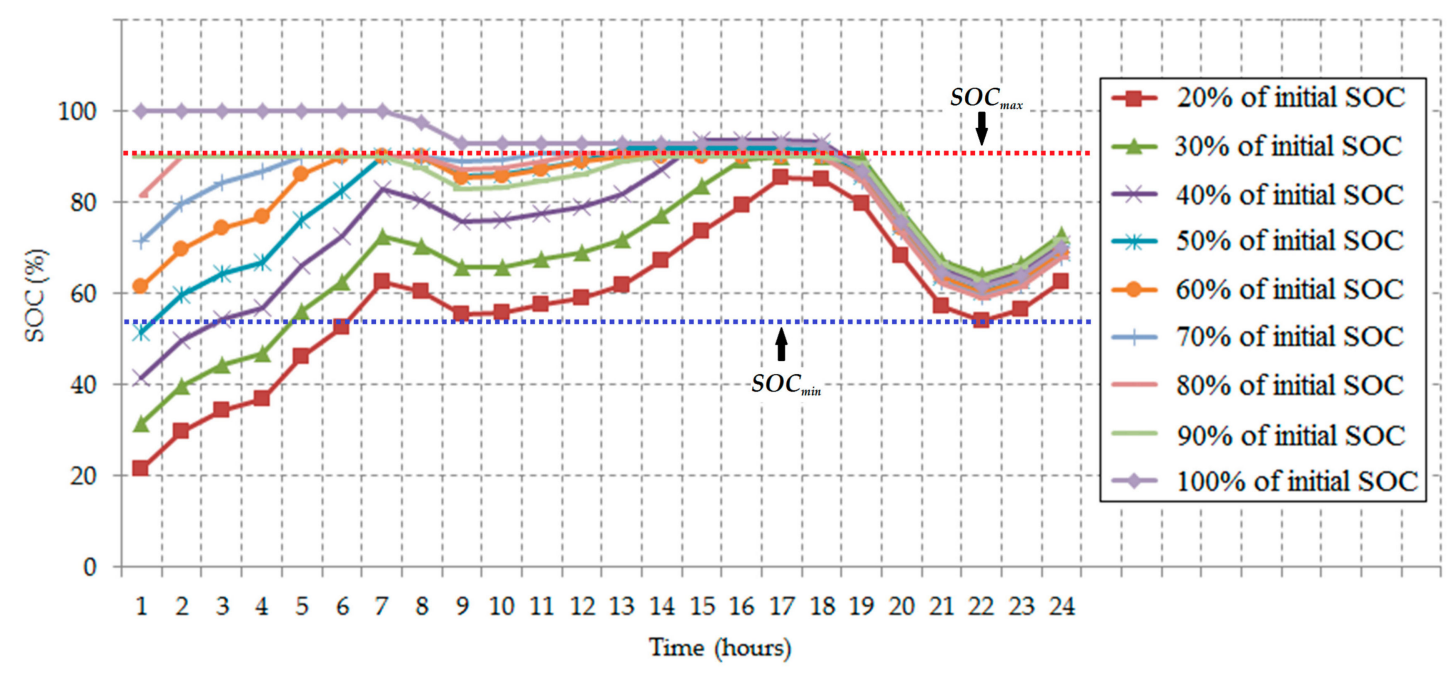

Figure 12. The SOC status of random selected EVs under the best optimized scenario.

Both $P_{d, a f t e r}$ and $P_{d, b e f o r e}$ can be calculated using Equations (14) and (15), respectively:

$$
\begin{gathered}
P_{d, a f t e r}=P_{p, a f t e r}-P_{v, \text { after }} \\
P_{d, \text { before }}=P_{p, \text { before }}-P_{v, \text { before }}
\end{gathered}
$$

where $P_{p, a f t e r}$ is the peak load value after V2G optimization, $P_{v, \text { after }}$ is the valley load value after V2G optimization, $P_{p, \text { before }}$ is the peak load value before $\mathrm{V} 2 \mathrm{G}$ optimization, and $P_{v, \text { before }}$ is the valley load value before $\mathrm{V} 2 \mathrm{G}$ optimization.

The V2G algorithm proposed in [55] was capable of performing peak shaving and valley filling control. The power grid loading before the implementation of V2G algorithm had $P_{p, \text { before }}$ of $1090 \mathrm{MW}$ and $P_{v, \text { before }}$ of $855 \mathrm{MW}$. With the execution of $\mathrm{V} 2 \mathrm{G}$ algorithm, the power grid loading presented $P_{p, \text { after }}$ of $1080 \mathrm{MW}$ and $P_{v, \text { after }}$ of $950 \mathrm{MW}$. Hence, the computed $P_{i}$ using (13) was $44.68 \%$. A similar investigation was conducted for the researches in [56,57], where the computed $P_{i}$ acquired was $46.89 \%$ and $36.84 \%$, respectively. The analysis was also investigated on the best scenario (V2G optimization with $60 \%$ of $S O C_{i, a v e}$ and $55 \%$ of $\left.T L C_{p c t}\right)$ in this paper. The power grid loading before the implementation of the proposed V2G algorithm presented $P_{p, \text { before }}$ of $4.6 \mathrm{MW}$ and $P_{v, \text { before }}$ of $1.3 \mathrm{MW}$. Meanwhile, the power grid loading after the employment of the V2G algorithm achieved $P_{p, a f t e r}$ of $2.5 \mathrm{MW}$ and $P_{v, a f t e r}$ of 2.1 MW. Thus, $P_{i}$ was acquired to be $87.88 \%$. By comparing with the other literatures, the proposed algorithm in this paper shows a better performance in terms of the percentage improvement of peak and valley load difference. The details of the comparative analysis are presented in Table 2. 
Table 2. Comparative analysis of the proposed algorithm with other approaches for grid load variance minimization.

\begin{tabular}{ccccc}
\hline Parameter & Ref. [55] & Ref. [56] & Ref. [57] & Proposed Algorithm \\
\hline$P_{p, \text { before }}(\mathrm{MW})$ & 1090 & 188 & 0.56 & 4.6 \\
$P_{v, \text { before }}(\mathrm{MW})$ & 855 & 98 & 0.37 & 1.3 \\
$P_{d, \text { before }}(\mathrm{MW})$ & 235 & 90 & 0.19 & 3.3 \\
$P_{p, \text { after }}(\mathrm{MW})$ & 1080 & 159.8 & 0.49 & 2.5 \\
$P_{v, \text { after }}(\mathrm{MW})$ & 950 & 112 & 0.37 & 2.1 \\
$P_{d, \text { after }}(\mathrm{MW})$ & 130 & 47.8 & 0.12 & 0.4 \\
$P_{i}(\%)$ & 44.68 & 46.89 & 36.84 & 87.88 \\
\hline
\end{tabular}

\section{Conclusions}

This paper has presented the development of a V2G optimization algorithm with the objective of minimizing the grid load variance by utilizing the grid-connected EVs to provide the peak load shaving (V2G) and load levelling services (G2V). The proposed algorithm was examined under various scenarios of varying $T L C_{p c t}$ and $S O C_{i, a v e}$ while complying with the crucial constraints, such as the grid power balance, initial SOC of EV battery, EV grid connection probability and EV grid connection duration. The simulation results had verified the effectiveness of the proposed algorithm in achieving the objective of the grid load variance minimization in all scenarios. A Performance Index was introduced in this paper to provide an excellent indication on the overall performance of the proposed V2G optimization algorithm. The best optimized scenario was achieved at $55 \%$ of $T L C_{p c t}$ and $60 \%$ of $S O C_{i, a v e}$, with a Performance Index of 0.965 . Moreover, all the participated EVs had complied with the preset SOC limits and tended to reach to a similar SOC level at the end of the V2G scheduling. This analysis aims to serve as a recommendation for the selection of $T L C_{p c t}$ based on the available historical data of $S O C_{i, a v e}$. As a future work, the optimal energy scheduling of an integrated system of EVs and renewable energy resources will be investigated.

Author Contributions: All authors contributed equally for the decimation of the research article in current form.

Conflicts of Interest: The authors declare no conflict of interest.

\section{References}

1. Global EV Outlook 2016: Beyond One Million Electric Cars. Available online: https://www.iea.org/ publications/freepublications/publication/Global_EV_Outlook_2016.pdf/ (accessed on 3 May 2017).

2. Hussain, S.; Al-ammari, R.; Iqbal, A.; Jafar, M.; Padmanaban, S. Optimization Of Hybrid Renewable Energy System Using Iterative Filter Selection Approach. IET Renew. Power Gener. 2017, 11, 1440-1445. [CrossRef]

3. Tiwaria, R.; Babu, N.R.; Sanjeevikumar, P. A Review on GRID CODES-Reactive power management in power grids for Doubly-Fed Induction Generator in Wind Power application. In Lecture Notes in Electrical Engineering; Springer: Berlin, Germany, 2017.

4. Hajizadeh, A.; Norum, L.E.; Hassanzadehc, F; Sanjeevikumar, P. An Intelligent Power Controller for Hybrid DC Micro Grid Power System. In Lecture Notes in Electrical Engineering; Springer: Berlin, Germany, 2018; in press.

5. Saraswathi, A.; Sanjeevikumar, P.; Sutha, S.; Blaabjerg, F.; Ertas, A.H.; Fedák, V. Analysis of Enhancement in Available Power Transfer Capacity by STATCOM Integrated SMES by Numerical Simulation Studies. Eng. Sci.Technol. Int. J. 2016, 19, 671-675.

6. Un-Noor, F.; Padmanaban, S.; Mihet-Popa, L.; Mollah, M.N.; Hossain, E. A comprehensive study of key electric vehicle $(\mathrm{EV})$ components, technologies, challenges, impacts, and future direction of development. Energies 2017, 10, 1217. [CrossRef]

7. Vavilapalli, S.; Umashankar, S.; Sanjeevikumar, P.; Ramachandramurthy, V.K. Design and Real-Time Simulation of an AC Voltage Regulator based Battery Charger for Large-Scale PV-Grid Energy Storage Systems. IEEE Access J. 2017. [CrossRef] 
8. Sridhar, V.; Sanjeevikumar, P.; Ramesh, V.; Mihet-Popa, L. Study and Analysis of Intelligent Microgrid Energy Management Solution with Distributed Energy Sources. Energies 2017, 10, 1419.

9. Bharatiraja, C.; Sanjeevikumar, P.; Siano, P.; Ramesh, K.; Raghu, S. Real Time Foresting of EV Charging Station Scheduling for Smart Energy System. Energies 2017, 10, 337.

10. Al-Nussairif, M.; Bayindir, R.; Sanjeevikumar, P.; Mihet-Popa, L.; Siano, P. Constant Power Loads (CPL) with Microgrids: Problem Definition, Stability Analysis and Compensation Techniques. Energies 2017, 10, 1656.

11. Hossain, E.; Perez, R.; Sanjeevikumar, P.; Siano, P. Investigation on Development of Sliding Mode Controller for Constant Power Loads in Microgrids. Energies 2017, 10, 1086. [CrossRef]

12. Ali, A.; Sanjeevikumar, P.; Twala, B.; Marwala, T. Electric Power Grids Distribution Generation System For Optimal Location and Sizing-An Case Study Investigation by Various Optimization Algorithms. Energies 2017, 10, 960.

13. Vavilapalli, S.; Sanjeevikumar, P.; Umashankar, S.; Mihet-Popa, L. Power Balancing Control for Grid Energy Storage System in PV Applications-Real Time Digital Simulation Implementation. Energies 2017, 10, 928.

14. Swaminathan, G.; Ramesh, V.; Umashankar, S.; Sanjeevikumar, P. Investigations of Microgrid Stability and Optimum Power sharing using Robust Control of grid tie PV Inverter. In Lecture Notes in Electrical Engineering; Springer: Berlin, Germany, 2018; in press.

15. Tamvada, K.; Umashankar, S.; Sanjeevikumar, P. Impact of Power Quality Disturbances on Grid Connected Double Fed Induction Generator. In Lecture Notes in Electrical Engineering; Springer: Berlin, Germany, 2018; in press.

16. Yong, J.Y.; Ramachandaramurthy, V.K.; Tan, K.M. A review on the state-of-the-art technologies of electric vehicle, its impacts and prospects. Renew. Sust. Energy Rev. 2015, 49, 365-385. [CrossRef]

17. Mwasilu, F.; Justo, J.J.; Kim, E.K.; Do, T.D.; Jung, J.W. Electric vehicles and smart grid interaction: A review on vehicle to grid and renewable energy sources integration. Renew. Sustain. Energy Rev. 2014, 34, 501-516. [CrossRef]

18. Gary, M.K.; Morsi, W.G. Power quality assessment in distribution systems embedded with plug-in hybrid and battery electric vehicles. IEEE Trans. Power Syst. 2015, 30, 663-671. [CrossRef]

19. Dharmakeerthi, C.H.; Mithulananthan, N.; Saha, T.K. A comprehensive planning framework for electric vehicle charging infrastructure deployment in the power grid with enhanced voltage stability. Int. Trans. Electr. Energy 2015, 25, 1022-1040. [CrossRef]

20. Kempton, W.; Letendre, S.E. Electric vehicles as a new power source for electric utilities. Transp. Res. Part D Transp. Environ. 1997, 2, 157-175. [CrossRef]

21. Krishna, M.; Daya, F.J.L.; Sanjeevikumar, P.; Mihet-Popa, L. Real-time Analysis of a Modified State Observer for Sensorless Induction Motor Drive used in Electric Vehicle Applications. Energies 2017, 10, 1077. [CrossRef]

22. Lund, H.; Kempton, W. Integration of renewable energy into the transport and electricity. Energy Policy 2008, 36, 3578-3587. [CrossRef]

23. Apostolaki-Iosifidou, E.; Codani, P.; Kempton, W. Measurement of power loss during electric vehicle charging and discharging. Energy 2017, 127, 730-742. [CrossRef]

24. Shinzaki, S.; Sadano, H.; Maruyama, Y.; Kempton, W. Deployment of vehicle-to-grid technology and related issues. SAE Tech. Pap. 2015. [CrossRef]

25. Tomić, J.; Kempton, W. Using fleets of electric-drive vehicles for grid support. J. Power Sources 2007, 168, 459-468. [CrossRef]

26. Kempton, W.; Tomić, J. Vehicle-to-grid power fundamentals: Calculating capacity and net revenue. J. Power Sources 2005, 144, 268-279. [CrossRef]

27. Hidrue, M.K.; Parsons, G.R.; Kempton, W.; Gardner, M.P. Willingness to pay for electric vehicles and their attributes. Resour. Energy Econ. 2011, 33, 686-705. [CrossRef]

28. Kempton, W.; Tomić, J. Vehicle-to-grid power implementation: From stabilizing the grid to supporting large-scale renewable energy. J. Power Sources 2005, 144, 280-294. [CrossRef]

29. Liu, C.; Chau, K.T.; Wu, D.; Gao, S. Opportunities and challenges of vehicle-to-home, vehicle-to-vehicle, and vehicle-to-grid technologies. Proc. IEEE 2013, 101, 2409-2427. [CrossRef]

30. Ghofrani, M.; Arabali, A.; Etezadi-Amoli, M.; Fadali, M.S. Smart scheduling and cost-benefit analysis of grid-enabled electric vehicles for wind power integration. IEEE Trans. Smart Grid 2014, 5, 2306-2313. [CrossRef] 
31. Manbachi, M.; Farhangi, H.; Palizban, A.; Arzanpour, S. A novel volt-VAR optimization engine for smart distribution networks utilizing vehicle to grid dispatch. Int. J. Electr. Power Energy Syst. 2016, 74, 238-251. [CrossRef]

32. Tan, K.M.; Ramachandaramurthy, V.K.; Yong, J.Y. Integration of electric vehicles in smart grid: A review on vehicle to grid technologies and optimization techniques. Renew. Sust. Energy Rev. 2016, 53, 720-732. [CrossRef]

33. Rao, S.; Berthold, F.; Pandurangavittal, K.; Blunier, B.; Bouquain, D.; Williamson, S.; Miraoui, A. Plug-in hybrid electric vehicle energy system using home-to-vehicle and vehicle-to-home: Optimization of power converter operation. In Proceedings of the IEEE Transportation Electrification Conference and Expo, Detroit, MI, USA, 16-19 June 2013; pp. 1-6.

34. Khederzadeh, M.; Maleki, H. Coordinating storage devices, distributed energy sources, responsive loads and electric vehicles for microgrid autonomous operation. Int. Trans. Electr. Energy 2015, 25, 2482-2498. [CrossRef]

35. Mejdoubi, A.E.; Oukaour, A.; Chaoui, H.; Gualous, H.; Sabor, J.; Slamani, Y. State-of-charge and state-of-health lithium-ion batteries' diagnosis according to surface temperature variation. IEEE Trans. Ind. Electron. 2015, 63, 2391-2402. [CrossRef]

36. Sortomme, E.; El-Sharkawi, M.A. Optimal combined bidding of vehicle-to-grid ancillary services. IEEE Trans. Smart Grid 2012, 3, 70-79. [CrossRef]

37. Shafie-Khah, M.; Heydarian-Forushani, E.; Osório, G.J.; Jamshid Aghaei, F.A.S.G.; Barani, M.; Catalão, J.P.S. Optimal behavior of electric vehicle parking lots as demand response aggregation agents. IEEE Trans. Smart Grid 2016, 7, 2654-2665. [CrossRef]

38. Nguyen, H.N.T.; Zhang, C.; Mahmud, M.A. Optimal coordination of G2V and V2G to support power grids with high penetration of renewable energy. IEEE Trans. Transp. Electrification 2015, 1, 188-195. [CrossRef]

39. Xie, S.; Zhong, W.; Xie, K.; Yu, R.; Zhang, Y. Fair energy scheduling for vehicle-to-grid networks using adaptive dynamic programming. IEEE Trans. Neural Netw. Learn. Syst. 2016, 27, 1697-1707. [CrossRef] [PubMed]

40. Amirioun, M.H.; Kazemi, A. A new model based on optimal scheduling of combined energy exchange modes for aggregation of electric vehicles in a residential complex. Energy 2014, 69, 186-198. [CrossRef]

41. Saber, A.Y.; Venayagamoorthy, G.K. Intelligent unit commitment with vehicle-to-grid-A cost-emission optimization. J. Power Sources 2010, 9, 898-911. [CrossRef]

42. Nafisi, H.; Abyaneh, H.A.; Abedi, M. Energy loss minimization using PHEVs as distributed active and reactive power resources: A convex quadratic local optimal solution. Int. Trans. Electr. Energy 2016, 26, 1287-1302. [CrossRef]

43. Nunes, P.; Farias, T.; Brito, M.C. Enabling solar electricity with electric vehicles smart charging. Energy 2015, 87, 10-20. [CrossRef]

44. Lee, W.; Xiang, L.; Schober, R.; Wong, V.W.S. Electric vehicle charging stations with renewable power generators: A game theoretical analysis. IEEE Trans. Smart Grid 2015, 6, 608-617. [CrossRef]

45. Jin, C.; Sheng, X.; Ghosh, P. Energy efficient algorithms for electric vehicle charging with intermittent renewable energy sources. In Proceedings of the IEEE Power and Energy Society General Meeting, Vancouver, BC, Canada, 21-25 July 2013; pp. 1-5.

46. Fazelpour, F.; Vafaeipour, M.; Rahbari, O.; Rosen, M.A. Intelligent optimization to integrate a plug-in hybrid electric vehicle smart parking lot with renewable energy resources and enhance grid characteristics. Energy Convers. Manag. 2014, 77, 250-261. [CrossRef]

47. Nan, Z.; Nian, L.; Jianhua, Z.; Jinyong, L. Multi-objective optimal sizing for battery storage of PV-based microgrid with demand response. Energies 2016, 9, 591. [CrossRef]

48. Gerards, M.E.T.; Hunrink, J.L. Robust peak-shaving for a neighborhood with electric vehicles. Energies 2016, 9, 594. [CrossRef]

49. López, M.A.; de la Torre, S.; Martín, S.; Aguado, J.A. Demand-side management in smart grid operation considering electric vehicles load shifting and vehicle-to-grid support. Electr. Power Energy Syst. 2015, 64, 689-698. [CrossRef]

50. Sortomme, E.; Hindi, M.M.; MacPherson, S.D.J.; Venkata, S.S. Coordinated charging of plug-in hybrid electric vehicles to minimize distribution system losses. IEEE Trans. Smart Grid 2011, 2, 198-205. [CrossRef] 
51. Sheikhi, A.; Bahrami, S.; Ranjbar, A.M.; Oraee, H. Strategic charging method for plugged in hybrid electric vehicles in smart grids; a game theoretic approach. Int. J. Electr. Power Energy Syst. 2013, 53, 499-506. [CrossRef]

52. Jian, L.; Zheng, Y.; Xiao, X.; Chan, C.C. Optimal scheduling for vehicle-to-grid operation with stochastic connection of plug-in electric vehicles to smart grid. Appl. Energy 2015, 146, 150-161. [CrossRef]

53. Jian, L.; Zhu, X.; Shao, Z.; Niu, S.; Chan, C.C. A scenario of vehicle-to-grid implementation and its double-layer optimal charging strategy for minimizing load variance within regional smart grids. Energy Convers. Manag. 2014, 78, 508-517. [CrossRef]

54. Kordkheili, R.A.; Pourmousavi, S.A.; Savaghebi, M.; Guerrero, J.M.; Nehrir, M.H. Assessing the potential of plug-in electric vehicles in active distribution networks. Energies 2016, 9, 34. [CrossRef]

55. Wang, Z.; Wang, S. Grid power peak shaving and valley filling using vehicle-to-grid systems. IEEE Trans. Power Deliv. 2013, 28, 1822-1829. [CrossRef]

56. Shinde, P.; Swarup, K.S. Optimal electric vehicle charging schedule for demand side management. In Proceedings of the International Conference on Sustainable Green Building and Communities (SGBC), Chennai, India, 18-20 December 2016; pp. 1-6.

57. Turker, H.; Hably, A.; Bacha, S. Housing peak shaving algorithm (HPSA) with plug-in hybrid electric vehicles (PHEVs): Vehicle-to-home (V2H) and vehicle-to-grid (V2G) concepts. In Proceedings of the Fourth International Conference on Power Engineering, Energy and Electrical Drives (POWERENG), Istanbul, Turkey, 13-17 May 2013; pp. 1-7.

58. Alam, M.J.E.; Muttaqi, K.M.; Sutanto, D. A controllable local peak-shaving strategy for effective utilization of PEV battery capacity for distribution network support. IEEE Trans. Ind. Appl. 2015, 51, 2030-2037. [CrossRef]

59. Sridhar, V.; Umashankar, S.; Sanjeevikumar, P. Decoupled Active and Reactive Power Control of Cascaded H-Bridge PV-Inverter for Grid Connected Applications. In Lecture Notes in Electrical Engineering; Springer: Berlin, Germany, 2018; in press.

60. Millner, A. Modeling lithium ion battery degradation in electric vehicles. In Proceedings of the IEEE Conference on Innovative Technologies for an Efficient and Reliable Electricity Supply, Waltham, MA, USA, 27-29 September 2010; pp. 349-356.

61. Camacho, O.M.F.; Nørgård, P.B.; Rao, N.; Mihet-Popa, L. Electrical vehicle batteries testing in a distribution network using sustainable energy. IEEE Trans. Smart Grid 2014, 5, 1033-1042. [CrossRef]

62. Jerin, A.R.A.; Palanisamy, K.; Sanjeevikumar, P.; Umashankar, S.; Ramachandramurthy, V.K. Improved Fault Ride Through Capability in DFIG based Wind Turbines using Dynamic Voltage Restorer with Combined Feed-Forward and Feed-Back Control. IEEE Access J. 2017. [CrossRef]

63. Tiwari, R.; Babu, N.R.; Arunkrishna, R.; Sanjeevikumar, P. Comparison between PI controller and Fuzzy logic based control strategies for harmonic reduction in Grid integrated Wind energy conversion system. In Lecture Notes in Electrical Engineering; Springer: Berlin, Germany, 2018; in press.

64. Tiwari, R.; Ramesh Babu, N.; Sanjeevikumar, P.; Martirano, L. Coordinated DTC and VOC Control for PMSG based Grid Connected Wind Energy Conversion System. In Proceedings of the 2017 IEEE International Conference on Environment and Electrical Engineering and 2017 IEEE Industrial and Commercial Power Systems Europe (EEEIC/I\&CPS Europe), Milan, Italy, 6-9 June 2017.

65. Chinthamalla, R.; Sanjeevikumar, P.; Karampuria, R.; Jain, S.; Ertas, A.H.; Fedak, V. A Solar PV Water Pumping Solution Using a Three-Level Cascaded Inverter Connected Induction Motor Drive. Eng. Sci. Technol. Int. J. 2016, 19, 1731-1741.

66. Jain, S.; Ramulu, C.; Sanjeevikumar, P.; Ojo, O.; Ertas, A.H. Dual MPPT Algorithm for Dual PV Source Fed Open-End Winding Induction Motor Drive for Pumping Application. Eng. Sci. Technol. Int. J. 2016, 19, 1771-1780. [CrossRef]

67. Swaminathan, G.; Ramesh, V.; Umashankar, S.; Sanjeevikumar, P. Fuzzy Based Micro Grid Energy Management System using Interleaved Boost Converter and Three Level NPC Inverter with Improved Grid Voltage Quality. In Lecture Notes in Electrical Engineering; Springer: Berlin, Germany, 2018; in press. 
68. Awasthi, A.; Karthikeyan, V.; Rajasekar, S.; Sanjeevikumar, P.; Siano, P.; Ertas, A.H. Dual Mode Control of Inverter to Integrate Solar-Wind Hybrid fed DC-Grid with Distributed AC grid. In Proceedings of the 16th IEEE International Conference on Environment and Electrical Engineering (IEEE-EEEIC'16), Florence, Italy, 7-10 June 2016.

69. Camacho, O.M.F.; Mihet-Popa, L. Fast Charging and Smart Charging Tests for Electric Vehicles Batteries using Renewable Energy. Oil Gas Sci. Technol. 2016, 71, 3.

(c) (1) 